\title{
Sintomas depressivos em crianças e adolescentes com anemia falciforme
}

Depressive symptoms in children and adolescents with sickle cell anemia

Felipe José Nascimento Barreto', Rosana Cipolotti²

\section{RESUMO}

Objetivo: Determinar a frequência de sintomas depressivos em crianças e adolescentes com anemia falciforme, bem como caracterizar e associar tal sintomatologia aos dados individuais. Métodos: Realizou-se um estudo transversal com portadores de anemia falciforme dos 7 aos 17 anos, atendidos em um ambulatório de Hematologia Pediátrica, os quais preencheram o Inventário de Depressão Infantil (CDI). Resultados: Foram avaliados 76 pacientes, estabelecendo-se em 13 o ponto de corte. Vinte e seis pacientes (34,2\%) apresentavam sintomas sugestivos de depressão. "Não ser tão bom quanto os outros colegas" foi o item mais pontuado, além de ter predominado significativamente naqueles com escore de CDI maior ou igual a 13, assim como as variáveis: ter pais separados ou viúvos e renda familiar mensal menor ou igual a $R \$ 510,00$. O item "preocupação com dores" foi bem pontuado, independentemente da presença de sintomas depressivos $(p=0,1)$. Conclusão: A depressão em crianças e adolescentes com anemia falciforme ainda é pouco estudada. Os dados obtidos indicam frequência elevada de sintomas depressivos nessa população. Possivelmente, conviver precocemente com a separação dos pais e pertencer a uma família com baixa renda esteja relacionado ao desenvolvimento desses sintomas.

\begin{abstract}
Objective: Determinate prevalence of depressive symptoms in children and adolescents with sickle cell anemia, characterize and associate then with individuals data. Methods: A transversal study was conducted with people with sickle cell anemia from 7 to 17 years old, followed at a Pediatric Hematology Center, which fulfilled the Children's Depression Inventory $(C D I)$. Results: A total of 76 children and adolescents were selected, considering a cut-off point of 13. Twenty-six patients $(34,2 \%)$ had suggestive symptoms of depression. "Not able to be as good as others siblings" was the most scored item of CDI, and it prevailed significantly in that with CDI score higher or equal than 13, as the variables: having divorced or widowed parents, and family income lower or equal to $R \$ 510,00$. The item "worries about pain" obtained high score whether depressive symptoms were present or not $(p=0,1)$. Conclusion: Depression in children and adolescents with sickle cell anemia remains poorly discussed. Data obtained indicates high rates of depressive symptoms in this population. Probably, early experience of parental separation and low family income may contribute to development of these symptoms.
\end{abstract}

1 Universidade Federal de Sergipe (UFS).

2 UFS, Departamento de Medicina.

\section{Keywords}

depressive symptoms, children, adolescents.
Recebido em $11 / 8 / 2011$ Aprovado em 21/10/2011

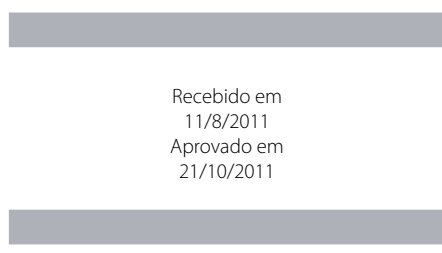

Endereço para correspondência: Felipe José Nascimento Barreto Praça Tobias Barreto, 220, ap. 302 - 49015-130 - Aracaju, SE Tel.: (79) 3224-9059

E-mail: lipegauche@hotmail.com 


\section{INTRODUÇÃO}

A anemia falciforme é uma doença autossômica recessiva caracterizada pela homozigose do gene codificador da hemoglobina mutante $\mathrm{S}$, que origina hemácias deformadas, propensas a hemólise e obstrução vascular ${ }^{1-3}$. Sua alta prevalência entre a população, mais precisamente naquelas em que a influência negra é predominante, faz dessa enfermidade um verdadeiro problema de saúde pública em várias partes do mundo 4 . Só no Brasil, 3.500 crianças nascem por ano com doença falciforme, grupo de hemoglobinopatias cuja principal representante é a anemia falciforme ${ }^{5}$.

Em curto ou longo prazo, as várias complicações inerentes ao estado falcêmico, quando não levam a óbito, constituem constante ameaça à qualidade de vida ${ }^{5,6}$. Desde cedo, os portadores de anemia falciforme já sofrem com os efeitos das crises álgicas, infecções e outras urgências significativas, que, invariavelmente, aumentam o número de hospitalizações e diminuem as horas dispensadas à escola e às demais atividades produtivas ${ }^{6-9}$.

O prejuízo funcional e social é notório e, por despontar já na infância e adolescência então, torna-se marcante para fases da vida tão cruciais para a construção da identidade adulta. Reflexo indireto do histórico de faltas por internações, o fraco desempenho escolar que muitos possuem favorece a repetência e dificulta o progresso acadêmico. O menor contato entre colegas é, em algum grau, uma realidade fatídi$\mathrm{ca}^{2,6,9,10}$. Não é incomum nessa faixa etária que os sinais físicos da anemia falciforme motivem a exclusão do portador dos círculos de amizade, muitas vezes, com a errônea justificativa de que possui uma enfermidade contagiosa"1.

Diante do convívio prematuro com tantos obstáculos impostos pela natureza incapacitante, incurável e fatal da anemia falciforme, sintomas depressivos podem vir à tona ainda na infância e adolescência ${ }^{12,13}$. E como toda doença crônica é por si só um fator de risco para depressão ${ }^{14}$, com a anemia falciforme não poderia ser diferente. Em adultos com anemia falciforme, taxas de depressão variam de 18\% a 44\%, valores similares aos encontrados para outras condições crônicas severas ${ }^{9}$.

Por sua vez, a depressão contribui de forma negativa no prognóstico da anemia falciforme ${ }^{10}$. Os sintomas depressivos são capazes de reduzir o limiar de tolerância para dor e a capacidade individual de lidar com essa experiência desagradável. O resultado é um aumento na frequência e intensidade das crises álgicas, maior número de admissões em pronto-socorro e internações e menor adesão ao esquema terapêutico ${ }^{6,7,13,14}$. Por fim, os sintomas depressivos em crianças e adolescentes são fortes preditores de transtorno depressivo maior, com ou sem ideação suicida, na fase adulta $a^{6,11}$.

$\mathrm{Na}$ literatura está bem estabelecida a associação entre depressão e doenças crônicas da infância ${ }^{14,15}$. Quanto à anemia falciforme, há muitos estudos avaliando depressão nos portadores adultos, porém poucos que contemplem crianças e adolescentes ${ }^{6,13}$. Tendo em vista as nuances da depressão sobre o desenvolvimento infanto-juvenil16, acredita-se que não seja adequado simplesmente adaptar para essa faixa etária os achados obtidos em adultos.

O presente estudo visa determinar a frequência de sintomas depressivos em crianças e adolescentes com anemia falciforme, caracterizar tal sintomatologia e correlacioná-la com dados individuais, antecedentes pessoais e familiares.

\section{MÉTODOS}

Entre julho de 2010 e março de 2011, realizou-se um estudo transversal com crianças e adolescentes atendidos em ambulatório de Hematologia Pediátrica de um hospital universitário, entre 7 a 17 anos e com diagnóstico confirmado de anemia falciforme. Além de estarem em seguimento regular no serviço por no mínimo seis meses e/ou duas consultas de rotina, tinham que ser alfabetizados e estar aptos a entender orientações verbais. Pacientes que foram hospitalizados há menos de um mês ou que apresentavam intercorrências agudas eram abordados em consultas posteriores.

As crianças e adolescentes elegíveis, bem como seus respectivos responsáveis, foram entrevistados por um único pesquisador no dia da consulta médica de rotina. Após esclarecimento sobre a natureza e os objetivos da pesquisa, paciente e responsável eram conduzidos a uma sala reservada. Com a autorização verbal e escrita, mediante assinatura de um Termo de Consentimento Livre e Esclarecido pelo responsável, foram coletados dados referentes à identificação do paciente e de seu principal cuidador, condições socioeconômicas da família, antecedentes familiares de doença psiquiátrica e de anemia falciforme.

A seguir, solicitou-se ao paciente que preenchesse o Inventário de Depressão Infantil ou Children's Depression Inventory $(\mathrm{CDI})^{17,18}$. Cada um dos 27 itens que o compõe possui três opções de resposta que correspondem a valores de 0 a 2 , conforme a gravidade dos sintomas depressivos. Coube ao sujeito da pesquisa assinalar a opção que melhor descrevesse seus pensamentos e sentimentos nas duas semanas anteriores à data da aplicação do CDI, tendo sido enfatizado que não há resposta certa ou errada e ratificado o sigilo dos dados fornecidos. Durante essa etapa, pesquisador e responsável aguardaram do lado de fora da sala até o completo preenchimento do inventário, a fim de garantir a privacidade do paciente e maior fidedignidade às suas respostas.

Elaborado por Kovacs ${ }^{17,18}$, o CDI representa uma adaptação do Inventário de Depressão de Beck às particularidades desse transtorno afetivo na população infanto-juvenil, servindo como método de triagem de sintomas sugestivos de depressão em indivíduos dos 7 aos 17 anos completos ${ }^{19}$. Nos seus 27 itens, cinco dimensões relevantes de quadros 
depressivos são avaliadas: humor negativo, problemas interpessoais, ineficiência, anedonia e autoestima negativa ${ }^{18}$.

O somatório da pontuação obtida fornece um escore que varia de 0 a 54, sendo estabelecido em 19 o ponto de corte para a presença de sintomas depressivos em amostras populacionais e em 13 o ponto de corte para amostras clíni$\operatorname{cas}^{19}$. No Brasil, o CDI foi inicialmente adaptado e normatizado por Gouveia et al. ${ }^{20}$, que reduziram o número de itens de 27 para 20, mantendo a consistência interna do instrumento, e sugeriram um ponto de corte de 17 para escolares e adolescentes brasileiros. Há ainda uma segunda versão brasileira do CDI, devidamente traduzida por Baptista ${ }^{21}$ e que, por sua vez, respeita a estrutura original de 27 itens. No presente estudo, optou-se por empregar esta última adaptação do CDI, além de fixar um ponto de corte maior ou igual a 13 para a presença de sintomas depressivos.

Os dados coletados foram analisados pelo programa EPI Info ${ }^{\oplus}$, versão 3.5.3. Para as variáveis contínuas, calcularam-se média e desvio-padrão, e para as discretas, fez-se a distribuição de frequências. Proporções foram comparadas pelos testes qui-quadrado ou de Fisher e comparações que envolviam médias, pelos testes ANOVA ou Mann-Whitney. Adotou-se um intervalo de confiança de $95 \%(p<0,05)$.

O projeto foi aprovado pelo Comitê de Ética em Pesquisa envolvendo seres humanos da Universidade Federal de Sergipe (CEP/UFS), sob o protocolo 0075.0.107.000-10.

\section{RESULTADOS}

Durante o período de coleta de dados, havia em seguimento ambulatorial 139 pacientes com idades entre 7 e 17 anos - 115 deles foram abordados, dos quais 76 pacientes eram elegíveis (Figura 1).

Dos 76 pacientes avaliados, 41 (53,9\%) eram meninos, com média de idade de 12,9 $\pm 2,73$ anos, sendo oito crianças
$(10,5 \%)$ e 68 adolescentes (89,5\%). A média de irmãos foi de 3,01 $\pm 2,44$ e a de número de pessoas no domicílio foi de 4,6 $\pm 1,88$. Quarenta e um pacientes $(53,9 \%)$ estavam com idade defasada para a série, ou seja, possuíam idade superior em no mínimo dois anos àquela recomendada para a série na qual se encontravam ${ }^{22}$.

No momento da avaliação, 35 pacientes $(46,1 \%)$ eram fiIhos de pais casados ou em união estável, 50,7\% moravam somente com a mãe e sete $(9,2 \%)$ eram órfãos de pai. Dentre os cuidadores, $68,6 \%$ relataram não ter ensino fundamental completo e $47,3 \%$ não exerciam trabalho remunerado. A média de renda mensal era de $\mathrm{R} \$ 842,63 \pm 591,08$ ( $\mathrm{R} \$ 90,00$ $\mathrm{R} \$ 3.000,00)$. Vinte e duas famílias $(28,9 \%)$ referiram renda mensal igual ou inferior a um salário-mínimo (R\$ 510,00 na época da coleta). Quarenta e um pacientes $(53,9 \%)$ recebiam auxílio-doença de um salário-mínimo do Instituto Nacional de Seguridade Social. Vinte pacientes (28,2\%) tinham outro portador de anemia falciforme no mesmo domicílio e 19 $(25,3 \%)$ apresentavam antecedente familiar de transtorno psiquiátrico.

Todas as crianças e adolescentes preencheram adequadamente o CDI, que apresentou um escore médio de 10,34 \pm 6,63 (0-31). Em 26 pacientes (34,2\%), o escore do CDI foi igual ou superior a 13, sugestivo de sintomas depressivos.

Os itens mais pontuados, em ordem decrescente, foram: 24 ("não ser tão bom quanto os outros colegas"), 19 ("preocupação com dores") e 15 ("esforço requerido para realizar tarefas escolares") (Figura 2). Tanto o item $24(p=0,017)$ quanto o $15(p=0,012)$, pertencentes ao domínio "Ineficiência" do CDI, predominaram de maneira significativa no grupo com sintomas depressivos, com exceção do item 19, que foi bem pontuado independentemente da presença ou não de sintomas depressivos $(p=0,1)$. Junto com o item 14 ("alteração da imagem corporal"), o item 9 ("ideação suicida") foi o décimo mais pontuado e, como o item 19, não predominou somente no grupo com sintomas depressivos (Figura 2).

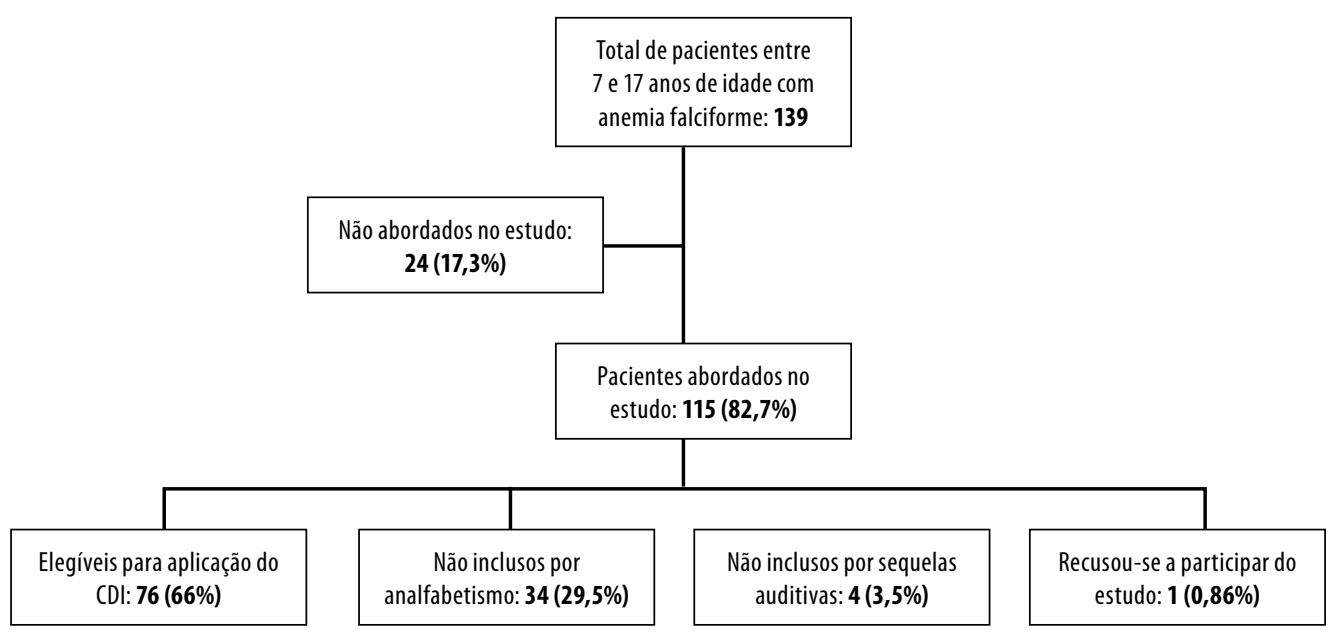

Figura 1. Fluxograma de alocação dos pacientes elegíveis para o estudo. 


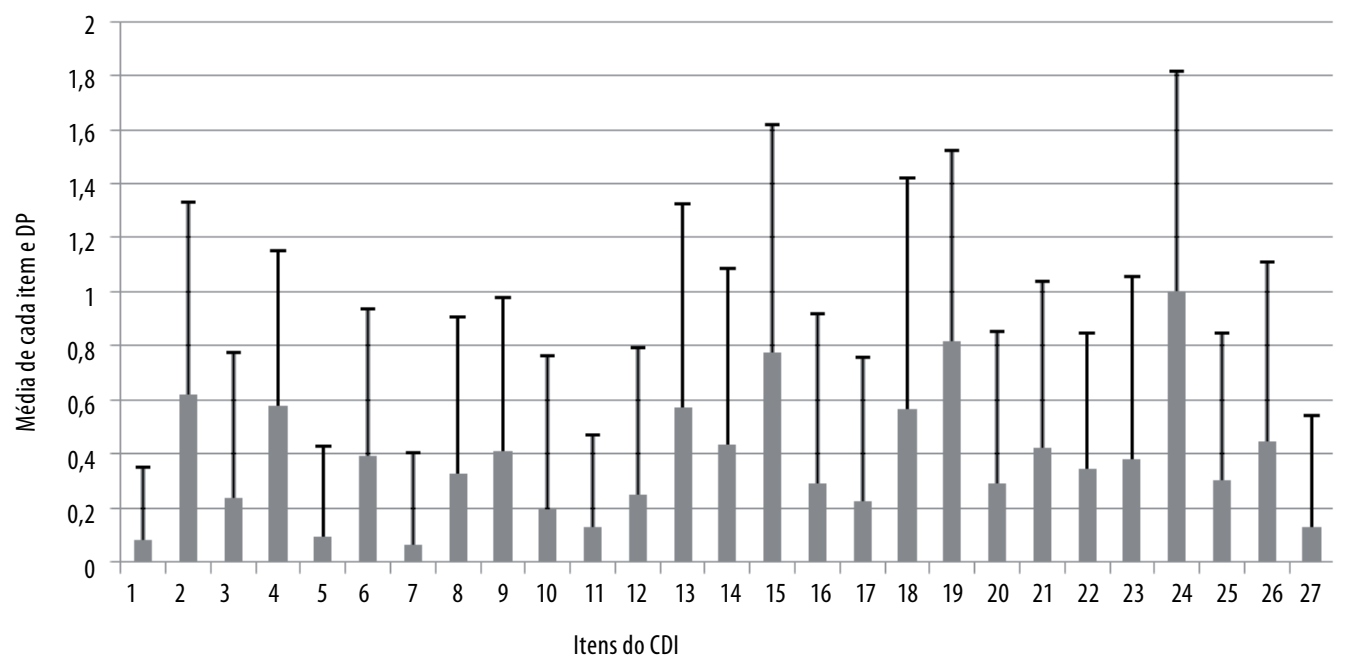

Figura 2. Distribuição da média dos 27 itens do CDI.

Quando se compararam as variáveis descritivas com os grupos que apresentaram escores do $C D I \geq 13$ e $<13$, houve uma diferença estatisticamente significante para os quesitos possuir pais separados ou viúvos ( $p<0,001)$ e renda familiar mensal $\leq R \$ 510,00(p=0,034)$ (Tabela 1). Também houve associação significativa entre aqueles com escore do CDI $\geq 13$ e a média calculada a partir da renda mensal $(p=0,002)$. Não se observou correlação entre as médias de idade dos pacientes, de número de irmãos e de pessoas que moram no mesmo domicílio.

Dentre os cinco domínios avaliados pelo CDI, o mais prevalente foi "Anedonia", seja nos pacientes com escore $\geq 13$ ou $<13$. Com base na figura 3 , verifica-se uma maior varia- ção entre as pontuações obtidas em cada domínio no grupo com escore $\geq 13$, ao contrário do grupo com escore $<13$ (Figura 3).

Fez-se ainda a análise de cada domínio do CDI com as variáveis: pais separados ou viúvos, idade, renda mensal, sexo, defasagem idade-série e escolaridade do cuidador. Assim, observou-se média significativamente maior entre adolescentes no domínio "Humor deprimido" ( $p=0,03)$. Também foram significativas as médias das pontuações obtidas nos domínios "Anedonia" e "Autoestima negativa" entre os pacientes com pais separados ou viúvos ( $p=0,001$ e $p=0,02$, respectivamente). Para as demais variáveis pareadas com as médias de cada domínio, não houve diferença estatística (Tabela 2).

Tabela 1. Comparação entre as variáveis descritivas e os grupos com escore do CDI $\geq 13(n=26)$ e $<13(n=50)$

\begin{tabular}{|c|c|c|c|c|c|c|c|}
\hline & & \multicolumn{2}{|c|}{$C D I \geq 13$} & \multicolumn{2}{|c|}{$\mathrm{CDI}<13$} & \multirow[t]{2}{*}{ Total } & \multirow[t]{2}{*}{ p } \\
\hline & & $\mathbf{n}$ & $\%$ & n & $\%$ & & \\
\hline \multirow[t]{2}{*}{ Sexo } & Masculino & 13 & 31,7 & 28 & 68,3 & 41 & \multirow{2}{*}{0,798} \\
\hline & Feminino & 13 & 37,1 & 22 & 62,9 & 35 & \\
\hline \multirow[t]{2}{*}{ Idade (OMS) } & Criança (< 10 anos) & 2 & 25 & 6 & 75 & 8 & \multirow{2}{*}{0,44} \\
\hline & Adolescente (10-20 anos) & 24 & 35,3 & 44 & 64,7 & 68 & \\
\hline \multicolumn{2}{|c|}{ Nasceram em Aracaju ou região metropolitana } & 11 & 34,4 & 21 & 65,6 & 33 & 0,826 \\
\hline \multicolumn{2}{|c|}{ Vivem em Aracaju ou região metropolitana } & 7 & 29,2 & 17 & 70,8 & 24 & 0,711 \\
\hline \multicolumn{2}{|c|}{ Defasagem idade-série presente } & 16 & 39 & 25 & 61 & 41 & 0,474 \\
\hline \multicolumn{2}{|c|}{ Pais separados ou viúvos } & 4 & 11,4 & 31 & 88,6 & 35 & $<0,001^{*}$ \\
\hline \multicolumn{2}{|l|}{ Órfãos de pai } & 3 & 42,9 & 4 & 57,1 & 7 & 0,45 \\
\hline \multicolumn{2}{|c|}{ Cuidador com pelo menos ensino fundamental completo } & 4 & 18,2 & 18 & 81,8 & 22 & 0,064 \\
\hline \multicolumn{2}{|c|}{ Cuidador sem trabalho remunerado } & 12 & 34,3 & 23 & 65,7 & 35 & 0,941 \\
\hline \multicolumn{2}{|c|}{ Renda mensal $\leq \mathrm{R} \$ 510$} & 12 & 54,5 & 10 & 45,5 & 22 & $0,034^{*}$ \\
\hline \multicolumn{2}{|c|}{ Ganha auxílio-doença } & 14 & 34,1 & 27 & 65,9 & 41 & 0,818 \\
\hline \multicolumn{2}{|c|}{ Antecedente de anemia falciforme no mesmo domicílio } & 5 & 25 & 15 & 75 & 20 & 0,394 \\
\hline \multicolumn{2}{|c|}{ Antecedente psiquiátrico na família } & 6 & 31,6 & 13 & 68,4 & 19 & 0,961 \\
\hline
\end{tabular}




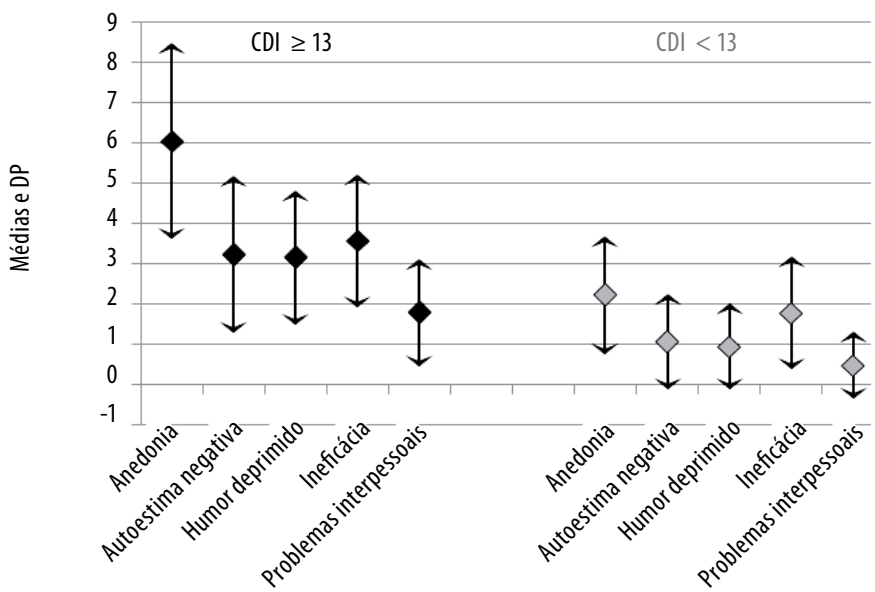

Figura 3. Distribuição das pontuações médias de cada domínio do CDI, com separação entre os grupos com escore de CDI $\geq 13$ e escore de $\mathrm{CDI}<13$.

Tabela 2. Análise comparativa entre as médias dos cinco domínios do CDI e as variáveis descritivas: faixa etária e situação conjugal dos pais

\begin{tabular}{|c|c|c|c|c|c|c|}
\hline \multirow[t]{2}{*}{ Domínios do CDI } & \multicolumn{3}{|c|}{ Faixa etária (OMS) } & \multicolumn{3}{|c|}{ Situação conjugal dos pais } \\
\hline & Criança & Adolescente & $p$ & Casados ou uniäo estável & Separados ou viúvos & $p$ \\
\hline Anedonia & $1,87 \pm 1,7$ & $3,72 \pm 2,6$ & 0,05 & $2,42 \pm 1,7$ & $4,46 \pm 2,8$ & $0,001^{*}$ \\
\hline Autoestima negativa & $0,75 \pm 0,8$ & $1,92 \pm 1,8$ & 0,08 & $1,31 \pm 1,5$ & $2,2 \pm 3,7$ & $0,02^{*}$ \\
\hline Humor deprimido & $0,62 \pm 0,7$ & $1,82 \pm 1,7$ & $0,03^{*}$ & $1,31 \pm 1,3$ & $2,02 \pm 1,8$ & 0,06 \\
\hline Ineficácia & $2,12 \pm 1,3$ & $2,42 \pm 1,7$ & 0,64 & $2,08 \pm 1,5$ & $2,65 \pm 1,8$ & 0,14 \\
\hline Problemas interpessoais & $1,12 \pm 2,0$ & $0,89 \pm 1,0$ & 0,7 & $0,88 \pm 1,4$ & $0,95 \pm 0,9$ & 0,26 \\
\hline
\end{tabular}

\section{DISCUSSÃO}

Na amostra analisada pelo estudo, houve ligeiro predomínio de meninos e uma nítida maioria de adolescentes. O uso da defasagem idade-série teve por objetivo identificar o desempenho escolar, que foi inadequado em pouco mais da metade dos pacientes. O nível de escolaridade também deixava a desejar em 68,6\% dos cuidadores, que tinham o ensino fundamental incompleto. Em 50,7\% dos casos, não havia um pai morando na casa do portador de anemia falciforme. No geral, as condições financeiras das famílias eram precárias, pois $47,3 \%$ dos cuidadores entrevistados nem trabalho remunerado possuíam. O auxílio-doença, benefício garantido por lei para custear as medicações e intercorrências ocorridas no curso de doenças crônicas como a anemia falciforme, só era cedido a $53,9 \%$ dos pacientes. Para $28,9 \%$ das famílias, a renda mensal relatada era de no máximo um salário-mínimo. Não foi frequente a positividade para antecedentes de transtornos psiquiátricos na família, ou de outro portador de anemia falciforme que residisse no mesmo domicílio dos sujeitos da pesquisa.
Estudos anteriores já apontavam para a presença de sintomas depressivos entre crianças e adolescentes com anemia falciforme. Em 1976, Kumar et al. ${ }^{23}$ compararam dois grupos de crianças, um com portadores de anemia falciforme e outro sem doenças crônicas, e encontraram resultados conflitantes. As crianças com anemia falciforme tinham mais comportamentos de esquiva social e menores índices de autoconceito do que o grupo controle, entretanto exibiam as mesmas taxas de problemas de ajustamento que os colegas sem a doença, e eram até menos ansiosas que estes ${ }^{23}$. Posteriormente, demonstrou-se que adolescentes com anemia falciforme vivenciam problemas de ajustamento mais severos do que aqueles normalmente experimentados por adolescentes fisicamente saudáveis. Foram encontrados pior rendimento acadêmico, menor satisfação com o corpo e maior tendência a evitar contato social no grupo com anemia falciforme do que no grupo controle. Esses autores foram pioneiros no uso do CDI em pacientes com anemia falciforme, encontrando neles médias significativamente maiores de escore $(9,04 \pm 5,8)$ do que nos que não apresentavam a doença $(4,54 \pm 3,6)^{24}$. 
Por intermédio do CDI com o ponto de corte 13, o presente estudo revelou sintomas sugestivos de depressão em 35,6\% da amostra de crianças e adolescentes com anemia falciforme. Um percentual congruente, embora menor do que esse, foi encontrado por Yang et al. ${ }^{25}$ em 36 pacientes de 6 a 18 anos que preencheram o Children's Depression Rating Scale-Revised (CDRS-R), uma escala de estrutura diferente, porém com finalidade semelhante à do CDI. Nesse estudo, 29\% dos portadores de anemia falciforme tiveram altos escores do CDRS-R, contra 12\% daqueles que compunham o grupo controle. Entretanto, quando ambos os grupos foram submetidos a uma entrevista psiquiátrica, a prevalência de depressão clínica não diferiu significativamente entre eles ${ }^{25}$.

Ainda no estudo de Yang et al., os quatro itens que contribuíram nos maiores escores de CDRS-R no grupo com anemia falciforme foram fadiga, queixas somáticas, preocupações sobre morte e problemas de autoestima ${ }^{25}$. Também fazendo uso de um instrumento de avaliação para sintomas depressivos, porém dirigida a pais e professores, Hijmans et al. ${ }^{26}$ encontraram maiores dificuldades escolares e queixas somáticas e menor interação social em crianças com doença falciforme do que nos seus colegas saudáveis. No presente estudo, os itens mais pontuados no CDI foram os relacionados ao domínio "Ineficácia" ("não ser tão bom quanto os outros colegas" e "esforço requerido para realizar tarefas escolares") e o item sobre "preocupação com dores", do domínio "Anedonia". Este último item foi bem pontuado tanto no grupo com escore de CDI $\geq 13$ quanto naquele com escore $<13$, sugerindo que a dor é sentida em ambos os grupos, não discriminando quem tem daqueles que não têm sintomas depressivos relevantes.

Quando comparadas as variáveis descritivas com os escores do CDI, houve associação significativa entre os quesitos que apontavam problemas conjugais e restrições financeiras e as crianças e adolescentes com sintomas depressivos relevantes. Por outro lado, fatores frequentemente relacionados à depressão infanto-juvenil, como história familiar de depressão ou perda do pai ${ }^{16}$, não foram observados entre os pacientes com escores do CDI $\geq 13$. Talvez o convívio precoce com a separação dos pais, a inclusão dos papéis paternos na figura da mãe e a renda familiar desfavorável interfiram negativamente na saúde mental dessas crianças e adolescentes, propiciando o desenvolvimento de sintomas depressivos.

O domínio mais pontuado do CDI foi "Anedonia", embora seja aquele que abarca maior número de itens entre os cinco domínios do instrumento. Esse achado encontra respaldo na literatura, que considera a anedonia como o componente mais específico da depressão em doentes crônicos, por ser, dentre toda a sintomatologia depressiva, aquele que menos é afetado pela condição de base ${ }^{27}$. Os escores significativamente maiores no domínio "Humor deprimido" entre os adolescentes estão em concordância com a literatu- ra, que destaca o humor deprimido como um dos sintomas mais prevalentes no adolescente com depressão ${ }^{16}$.

A avaliação específica de depressão em crianças e adolescentes com anemia falciforme ainda é objeto de poucos estudos, e no Brasil nenhum estudo dessa natureza foi encontrado na literatura pesquisada. Mesmo a literatura existente em nível mundial apresenta diferenças metodológicas que dificultam a interpretação de seus resultados. Sobre as duas versões brasileiras do CDI, a opção deste estudo foi por utilizar o inventário com 27 itens traduzido por Baptista ${ }^{21}$, em vez daquele de 20 itens de Gouveia et al. ${ }^{20}$. Sabe-se que ambas cumprem bem o papel de triagem para sintomas depressivos e, por esse motivo, são utilizadas com frequência no meio científico brasileiro. No entanto, a versão com 27 itens, cuja configuração é mais fiel ao CDI original, apresenta um índice mais alto de consistência interna quando comparado com a versão reduzida ${ }^{19}$. Um dos sete itens a mais inclusos no CDI com 27 itens, "preocupação com dores", foi o segundo mais pontuado entre os pacientes deste estudo.

Algumas dificuldades merecem destaque, como a considerável parcela de portadores de anemia falciforme que não são alfabetizados, os quais, pela exigência de o CDI ser autoaplicável, não puderam ser incluídos. Isso não só restringiu o tamanho da amostra como deixou de fora um grupo de indivíduos que já poderiam estar sofrendo com consequências da depressão em faixas etárias precoces, como o fraco desempenho escolar. Apesar de ser uma limitação do estudo, optou-se por não utilizar um grupo controle constituído de crianças e adolescentes saudáveis, uma vez que os pontos de corte do CDI são diferentes para populações clínicas e não clínicas. Não houve, também, uma avaliação psiquiátrica concomitante à coleta dos dados, já que o CDI não se presta ao diagnóstico de depressão clínica, mas à identificação de sintomas depressivos.

Muitos desafios do dia a dia ainda precisam ser superados por aqueles que padecem da anemia falciforme. Sentimentos de desesperança e baixa autoestima subsequente a hospitalizações frequentes, dor e absenteísmo escolar são queixas comuns desses jovens enfermos ${ }^{28}$ e podem sinalizar quadros depressivos em curso. Ainda é pequena a importância dada a esse transtorno afetivo em condições crônicas, sendo o seu subdiagnóstico nessas populações mais a regra do que a exceção. Além de sua sintomatologia se confundir muitas vezes com aquela da patologia de base, a depressão ainda é encarada por alguns profissionais, erroneamente, como uma reação "normal" à condição médica subjacente ${ }^{29}$.

\section{CONCLUSÃO}

Diante da elevada proporção de sintomas depressivos na amostra estudada, acredita-se que a saúde mental das crianças e adolescentes com anemia falciforme não deva 
ser relegada a um segundo plano nas consultas de rotina. A implantação de meios de triagem para sintomas depressivos, ou mesmo capacitação de hematologistas e demais profissionais médicos, pode ser uma estratégia benéfica. Intervenções de cunho preventivo e terapêutico organizadas por equipes multidisciplinares devem ser fomentadas. Todavia, não haverá soluções realmente eficazes se não se compreender o meio em que vive o portador de anemia falciforme, suas condições de escolaridade e aspectos socioeconômicos inerentes à sua família.

\section{AGRADECIMENTOS}

À Profa. Msc. Karla Maria Nunes Ribeiro, pelas importantes sugestões e críticas ao projeto e à versão final deste estudo.

\section{CONFLITOS DE INTERESSE}

Não há.

\section{REFERÊNCIAS}

1. Araújo PIC, Bandeira FMGC, Figueira CMG, Toscano RA. Doença falciforme. In: Lopez FA, Júnior DC. Tratado de Pediatria - Sociedade Brasileira de Pediatria. 2. ed. Barueri: Manole; 2010. v. 2.

2. Felix AA, Souza HM, Ribeiro SBF. Aspectos epidemiológicos e sociais da doença falciforme. Rev Bras Hematol Hemoter. 2010;32(3):203-8.

3. Zago MA, Pinto ACS. Fisiopatologia das doenças falciformes: da mutação genética à insuficiência de múltiplos órgãos. Rev Bras Hematol Hemoter. 2007;29(3):207-14.

4. Batista A, Andrade TC. Anemia falciforme: um problema de saúde pública no Brasil. Univ Ci Saúde. 2005;3(1):83-99.

5. Cançado RD, Jesus JA. A doença falciforme no Brasil. Rev Bras Hematol Hemoter. 2007;29(3):204-6

6. Benton TD, Ifeagwu JA, Smith-Whitley K. Anxiety and depression in children and adolescents with sickle cell disease. Curr Psychiatry Rep. 2007:9(2):114-21.

7. Felix AA. Aspectos clínico-epidemiológicos e percepção de dor na doença falciforme [dissertação]. Uberaba: Universidade Federal do Triângulo Mineiro; 2009.

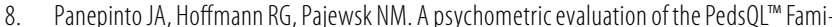
ly Impact Module in parents of children with sickle cell disease. Health Qual Life Outcomes. 2009;7(32)
9. Levenson JL. Psychiatric issues in adults with sickle cell disease. Primary Psychiatry. 2008;15(5):45-9.

10. Alao A0, Dewan MJ, Jindal S, Effron M. Psychopathology in sickle cell disease. West Afr J Med. 2003;22(4):334-7.

11. Jerenette C, Funk M, Murdaugh C. Sickle cell disease: a stigmatizing condition that may lead to depression. Issues Ment Health Nurs. 2005;26(10):1081-101.

12. Comer EW. Integrating the health and mental health needs of the chronically ill: a group for individuals with depression and sickle cell disease. Soc Work Health Care. 2004;38(4):57-76.

13. Hasan SP, Hashmi S, Alhassen M, Lawson W, Castro 0. Depression in sickle cell disease. J Natl Med Assoc. 2003;95(7):533-7.

14. Prager LM. Depression and suicide in children and adolescents. Pediatr Rev. 2009;30(6):199-206.

15. Ribeiro KMN. Sintomas depressivos em crianças e adolescentes com câncer [dissertação]. Aracaju: Universidade Federal de Sergipe; 2008.

16. Bahls SC. Aspectos clínicos da depressão em crianças e adolescentes. J Pediatr (Rio J). 2002;78(5):359-66.

17. Kovacs M. The Children Depression Inventory (CDI). Psychopharmacol Bull. 1985;21(4):995-8.

18. Kovacs M. Children's Depression Inventory Manual. New York: Multi-Health Systems, Inc. Toronto; 1992

19. Cruvinel M, Boruchovitch E, Santos AAA. Inventário de Depressão Infantil (CDI): análise dos parâmetros psicométricos. Fractal Rev Psicol. 2008;20(2):473-90.

20. Gouveia VV, Barbosa GA, Almeida HJF, Gaião AA. Inventário de Depressão Infantil - CDI - estudo de adaptação com escolares de João Pessoa. J Bras Psiquiatr. 1995;44(7):345-9.

21. Baptista MN. Depressão e suporte familiar: perspectivas de adolescentes e suas mães [dissertação]. Campinas: Pontifícia Universidade Católica de Campinas; 1997.

22. IBGE - Instituto Brasileiro de Geografia e Estatística. Síntese de indicadores sociais - uma análise das condições de vida da população brasileira. Rio de Janeiro; 2008. (Série Estudos e Pesquisas. Informação Demográfica e Socioeconômica, 23).

23. Kumar S, Powars D, Allen J, Haywood LJ. Anxiety, self-concept, and personal and social adjustments in children with sickle cell anemia. J Pediatr. 1976;88(5):859-63.

24. Morgan SA, Jackson J. Psychological and social concomitants of sickle cell anemia in adolescents. J Pediatr Psychol. 1986;11(3):429-40.

25. Yang YM, Cepeda M, Price C, Shah A, Mankad V. Depression in children and adolescents with sickle-cell disease. Arch Pediatr Adolesc Med. 1994;148(5):457-60.

26. Hijmans CT, Grootenhius MA, Oosterlaan J, Last BF, Heijboer H, Peters M, et al. Behavioral and emotional problems in children with sickle cell disease and healthy siblings: multiple informants, multiple measures. Pediatr Blood Cancer. 2009;53(7):1277-83.

27. Shemesh E, Yehuda R, Rockmore L, Shneider BL, Emre S, Bartell AS, et al. Assessment of depression in medically ill children presenting to pediatric specialty clinics. J Am Acad Child Adolesc Psychiatry. 2005;44(12):1249-57.

28. Anie KA. Psychological complications in sickle cell disease. Br J Haematol. 2005;129(6):723-9.

29. Teng CT, Humes EC, Demetrio FN. Depressão e comorbidades clínicas. Rev Psiq Clín. 2005:32(3):149-59. 